\title{
Logic Programming and Artificial Neural Networks in Breast Cancer Detection
}

\author{
José Neves $^{1(\bowtie)}$, Tiago Guimarães ${ }^{2}$, Sabino Gomes ${ }^{2}$, Henrique Vicente ${ }^{3}$, \\ Mariana Santos ${ }^{4}$, João Neves ${ }^{5}$, José Machado ${ }^{1}$, and Paulo Novais ${ }^{1}$ \\ ${ }^{1}$ Algoritmi, Universidade do Minho, Braga, Portugal \\ \{jneves, jmac, pjon\}@di.uminho.pt \\ ${ }^{2}$ Departamento de Informática, Universidade do Minho, Braga, Portugal \\ \{tiago.sguimaraes, sabinogomes.antonio\} @gmail.com \\ ${ }^{3}$ Departamento de Química, Centro de Química de Évora, \\ Escola de Ciências e Tecnologia, Universidade de Évora, Évora, Portugal \\ hvicente@uevora.pt \\ ${ }^{4}$ Escola de Ciências da Saúde, Universidade do Minho, Braga, Portugal \\ marianamltsantos@gmail.com \\ ${ }^{5}$ Drs. Nicolas \& Asp, Dubai, United Arab Emirates \\ joaocpneves@gmail.com
}

\begin{abstract}
About $90 \%$ of breast cancers do not cause or are capable of producing death if detected at an early stage and treated properly. Indeed, it is still not known a specific cause for the illness. It may be not only a beginning, but also a set of associations that will determine the onset of the disease. Undeniably, there are some factors that seem to be associated with the boosted risk of the malady. Pondering the present study, different breast cancer risk assessment models where considered. It is our intention to develop a hybrid decision support system under a formal framework based on Logic Programming for knowledge representation and reasoning, complemented with an approach to computing centered on Artificial Neural Networks, to evaluate the risk of developing breast cancer and the respective Degree-of-Confidence that one has on such a happening.
\end{abstract}

Keywords: Breast Cancer - Tyrer-Cuzick Model · Knowledge Representation and Reasoning · Logic Programing · Artificial Neural Networks 